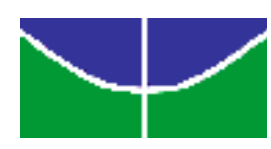

Universidade de Brasília - UnB

Faculdade de Economia, Administração, Contabilidade e Ciência da Informação e Documentação - FACE

Programa de Pós-Graduação em Administração - PPGA

\title{
A Política de Capacitação da Universidade de Brasília: a visão dos servidores técnicos administrativos
}

Odalva de Araújo Costa Otávio

Brasília - DF

2009 
Odalva de Araújo Costa Otávio

A Política de Capacitação da Universidade de Brasília: a visão dos servidores técnicos administrativos

Monografia apresentada ao Programa de Pós-Graduação em Administração da Faculdade de Economia, Administração, Contabilidade e Ciência da Informação e Documentação - FACE, da Universidade de Brasília, como parte dos requisitos para a obtenção do título de Especialista em Desenvolvimento Gerencial: Gestão Universitária.

Orientadora: Prof. Drª . Marilde Loiola de Menezes

$$
\begin{gathered}
\text { Brasília - DF } \\
2009
\end{gathered}
$$




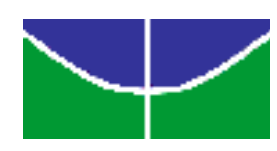

Universidade de Brasília - UnB

Faculdade de Economia, Administração, Contabilidade e Ciência da Informação e Documentação - FACE

Programa de Pós-Graduação em Administração - PPGA

\section{A Política de Capacitação da Universidade de Brasília: a visão dos servidores técnicos administrativos}

Odalva de Araújo Costa Otávio

Comissão Examinadora

$\overline{\text { Professora Doutora Marilde Loiola de Menezes }}$

(Orientadora)

\footnotetext{
Professor Doutor Paulo César Nascimento (Membro)
} 
Dedico a Osvaldo, meu esposo, e aos nossos filhos Mikaelle, Michelle e Marcello, por darem muito mais sentido e alegria à minha vida. 


\section{AGRADECIMENTO}

A Deus, criador de tudo;

A minha orientadora, professora Marilde Loiola de Menezes, que desde os primeiros contatos nas orientações deste trabalho exaltou minha capacidade, incentivando-me a acreditar que seria possível;

Ao professor Paulo César Nascimento, pela sua simpatia e pelo aceite imediato em compor a comissão examinadora;

Ao Sr. Onias, meu pais, já se foi do nosso convívio na Terra, mas em espírito sempre estará presente em todas as minhas vitórias. Afinal a formação inicial da minha personalidade e o meu desempenho na vida profissional são frutos, também, de muitos exemplos dados por ele em vida;

A minha mãe Emília, pelo amor e formação que me proporcionou; sem bons primeiros passos, a jornada fica muito mais difícil;

A Maria, minha irmã, que me incentivou a ingressar na pós-graduação e auxilioume sempre que precisei a procura de livros pela Biblioteca da UnB;

Ao meu esposo, Osvaldo e aos filhos, Mikaelle, Michelle e Marcello, pelo carinho, incentivo e compreensão nos momentos de ausência, por me incentivar a seguir em frente mesmo quando o caminho parecia difícil de trilhar;

Aos colegas do curso de pós-graduação, Dina, Lia e Walder, pela amizade, companheirismo e troca de conhecimento durante o curso;

Ao colega de trabalho, Gustavo, pela ajuda na criação das figuras e pelos comentários a respeito deste trabalho;

Aos colegas de trabalho em Relações Internacionais da Universidade de Brasília, Vanderlei, Telma e Anderson Xavier pelo incentivo de ingressar neste curso.

À Vera Oliveira secretária do curso de especialização pela sua simpatia. 
"Deus nos fez perfeitos e não escolhe os capacitados - capacita os escolhidos." Fazer ou não fazer algo só depende de nossa vontade e perseverança. Albert Einstein. 


\section{LISTA DE FIGURA}

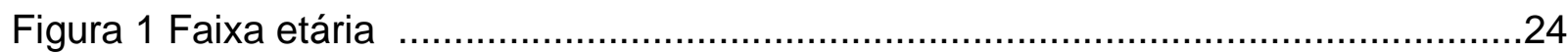

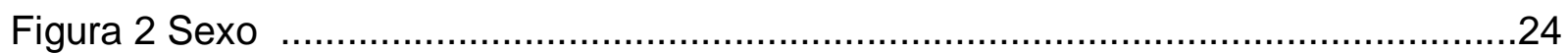

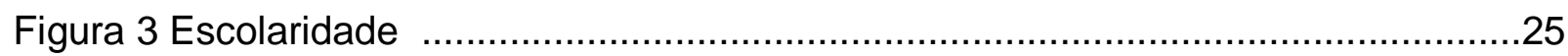

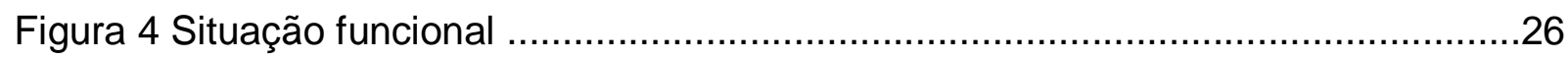

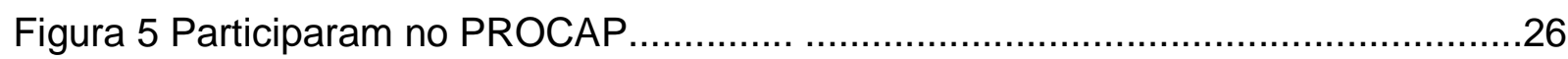

Figura 6 Servidores que tiveram problema de liberação do seu expediente de trabalho

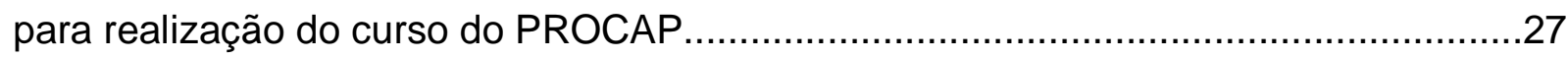

Figura 7 Relação entre o PROCAP e aumento na cultura geral do servidor ..................28

Figura 80 Procap como condutor de atualização sobre as principais abordagens do mundo do trabalho (relação pessoal, clareza nas decisões, uso de novas tecnologias)

Figura 9 Conteúdo oferecido pelo PROCAP e o desenvolvimento das atividades exercidas na Universidade de Brasília. 29

Figura 10 aplicação do conhecimento adquirido durante o curso no seu trabalho diário. 30

Figura 11 Qualificação do corpo docente do PROCAP 31

Figura 12 Recursos fornecidos pelo PROCAP (sala de aula, equipamento, luminosidade, sanitário, bebedouro e cantina) ..............................................32 


\section{LISTA DE TABELA}

Tabela 1 Evolução do numero de atividades de capacitação de pessoal ......................33

Tabela 2 Relação de Afastamento de Técnicos para Capacitação - 2002 ...................34

Tabela 3 Relação de Afastamento de Técnicos para Capacitação - 2003 ...................34

Tabela 4 Relação de Afastamento de Técnicos para Capacitação - 2004 ...................35

Tabela 5 Relação de Afastamento de Técnicos para Capacitação - 2005 ...................35

Tabela 6 Programa Quartas Gerenciais - 1999-2003 .............................................35

Tabela 7 Programa de preparação para educação básica - 1999-2005 ......................36 


\section{SUMÁRIO}

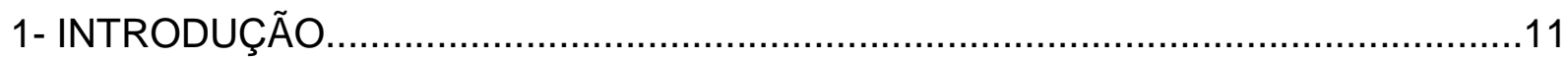

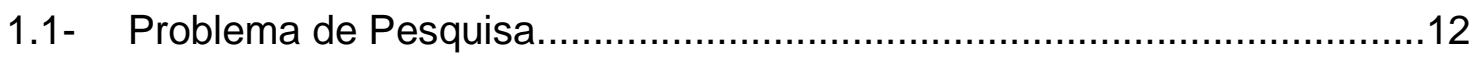

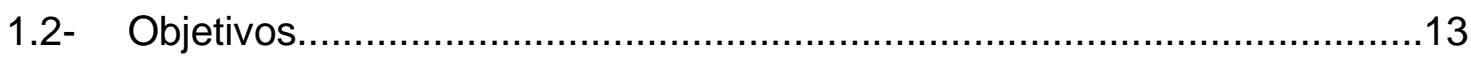

1.2.1- Objetivo Geral............................................................... 13

1.2.2- Objetivo Específico..............................................................13

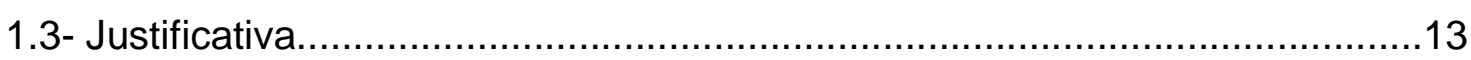

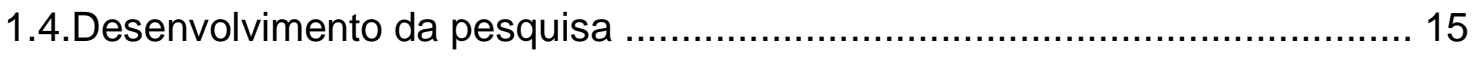

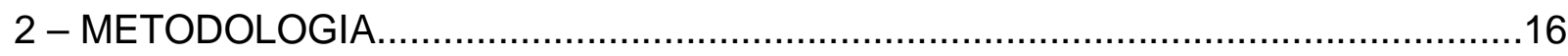

2.1 - Característica da Organização e tipo de Pesquisa....................................16

2.2 - Participantes da pesquisa ...................................................................16

2.3 - Instrumento da Coleta dos Dados..................................................... 17

2.4 - Procedimentos da Coleta de Dados....................................................... 17

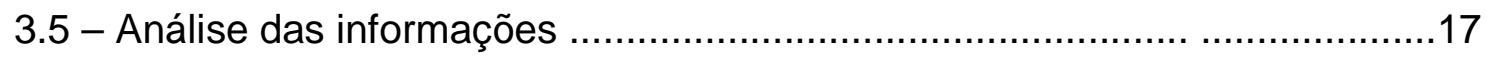

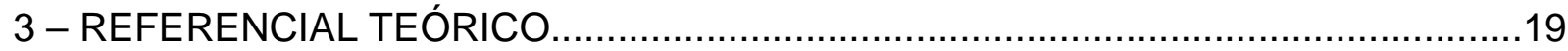

3.1 - Da Capacitação.................................................................................. 19

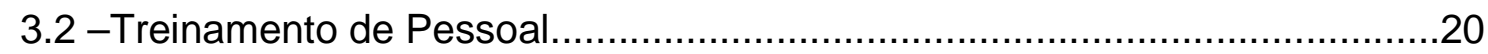

4 - POLÍTICA DE CAPACITAÇÃO: A VISÃO DOS SERVIDORES TÉCNICOADMINISTRATIVOS DA UNIVERSIDADE DE BRASÍLIA …...............................22

4.1 - O programa de Capacitação Profissional (PROCAP) ….............................22

4.2 - A visão dos servidores sobre o PROCAP ..............................................23

5 - DEMONSTRATIVOS DOS CURSOS RELAZIZADOS PELO PROCAP.....................33

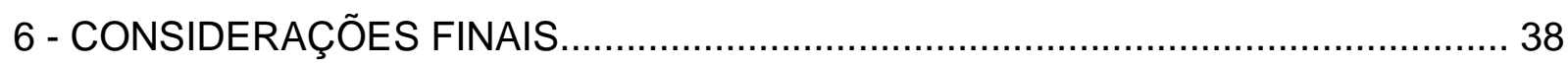

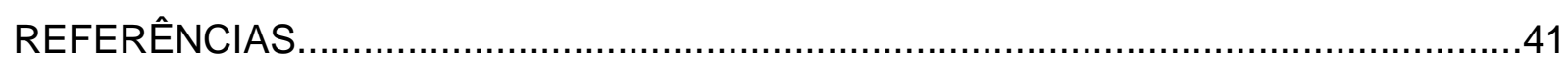

ANEXO 


\section{RESUMO}

Esse estudo tem como objetivo a análise da política de capacitação da Universidade de Brasília a partir das diferentes visões e percepções dos servidores que tiveram participação em cursos de formação no Programa de Capacitação Profissional (PROCAP) entre o período de 1995 a 2005. Os resultados apontados pelo estudo tem como objetivo dar subsídio ao gestores da Universidade de Brasília no sentido de ampliar a avaliação da política de capacitação de Recursos Humanos através da análise crítica do seu público alvo, isto é, dos servidores da Universidade de Brasília.

Palavras-chave: capacitação, treinamento e PROCAP. 


\section{1- INTRODUÇÃO}

Brasília tinha apenas dois anos quando ganhou oficialmente sua universidade federal. Inaugurada em 21 de abril de 1962, a Universidade de Brasília (UnB) já funcionava desde o início do mês, exatamente no dia 9, nas dependências do Ministério da Saúde, na Esplanada dos Ministérios. A data marcou o começo das aulas para os 413 alunos que haviam prestado o primeiro vestibular e, com ele, o da própria instituição que viria a se tornar uma das mais bem conceituadas do Brasil. Atualmente a Universidade compreende um total de 2.230 servidor-técnicos, 2.082 prestadores de serviço, 1.400 professores, 33.277 estudantes, sendo 24.381 de graduação e 8.896 de pós-graduação ${ }^{1}$

Em junho de 1995 foi criada a Coordenadoria de Capacitação da Secretária de Recursos Humanos da Universidade de Brasília com o objetivo de desenvolver atividades de capacitação, visando ao atendimento das reais demandas dos servidores da Universidade.

Para atender tais demandas foi criado o Programa de Capacitação Profissional (PROCAP) cursos diversificados em várias categorias nas áreas de Educação, Gerencial, Humanas, Informática, Língua estrangeira e técnica, com o objetivo de atender os interesses e necessidades dos servidores.

Atualmente a Universidade de Brasília oferece uma ampla oferta de cursos de capacitação para os servidores da Universidade, visando à qualidade dos seus serviços, o aperfeiçoamento de desempenhos, o aumento de produtividade, a melhoria da qualidade de vida, da qualificação profissional e das relações interpessoais. Tais iniciativas têm como objeto comum a preparação e adequação do perfil dos servidores e colaboradores aos diversos ambientes organizacionais, na formação do potencial humano frente às inovações tecnológica e as constantes mudanças do mercado de trabalho.

A PROCAP/Coordenaria de Recursos Humanos da Universidade de Brasília tem por missão a atualização dos Recursos Humanos desta Instituição, visando à qualidade dos seus serviços, e por princípios a melhoria da qualidade de vida da qualificação profissional; a adequação do perfil de servidores e colaboradores aos diversos

\footnotetext{
${ }^{1}$ Informações disponíveis na página: www.unb.br
} 
ambientes organizacionais; a valorização da sua participação nos programas desta Universidade e o processo contínuo de treinamento com agente motivador de participação.

Para fins deste estudo, foi analisada a política de capacitação da Universidade de Brasília a partir das diferentes visões e percepções dos servidores que tiveram participação em cursos de formação do Programa de Capacitação Profissional (PROCAP). A idéia é ampliar a avaliação da política de capacitação de Recursos Humanos através da análise crítica do seu público alvo, isto é, dos servidor-técnicos da Universidade de Brasília.

\section{1 - O problema de pesquisa}

A questão da capacitação dos servidores tem sido uma preocupação recorrente da Universidade de Brasília com o objetivo de desenvolver atividades de capacitação, visando ao atendimento das reais demandas do trabalho, às necessidades da Universidade e da sociedade, valorizando o treinamento e a capacitação funcional como processo permanentes e contínuos, que podem tornar-se ferramentas eficazes, dinâmicas e rápidas, como processo educativos por excelência, enquanto facilitadores da aprendizagem, do crescimento e do desenvolvimento psicossocial e intelectual dos servidores.

Apenas definir políticas e estratégicas não é suficiente, como afirmam Fleury e Oliveira Jr. (2001) deverá haver uma forma prática de alcançá-las, estimulando os talentos e habilidades dos empregados da organização. Portanto, uma razoável forma de pensar o processo de capacitação continuada e de aprendizagem, assim como a gestão de conhecimento nas organizações e considerá-los como uma estratégia organizacional, seria tê-los como fator que motive os servidores a procurar alcançar os objetivos estratégicos da organização.

Inseridas em um ambiente cada vez mais turbulento, as organizações precisam continuamente se preparar para as mudanças, superando deficiências de aprendizado e tornando-se cada vez mais eficazes. Ao mesmo tempo em que o ambiente organizacional torna-se mais aberto, exige igualmente qualificações mais amplas e 
flexíveis. Porém não basta atualização técnica, é preciso desenvolver um conjunto de competências básicas no ambiente de negócios, que garantam à organização um leque de vantagens competitivas.

Tendo como base esses referenciais a pesquisa procurou se desenvolver tendo como ponto de partida o conjunto de percepções dos servidores da Universidade de Brasília sobre a referida política.

\section{2 - Objetivos}

\subsection{1 - Objetivo Geral}

Analisar os impactos da política de capacitação de recursos humanos da Universidade de Brasília em termos da formação profissional, da racionalização do trabalho bem como da progressão funcional daqueles que se beneficiaram da referida política. Aos dados oficiais fornecidos pela Secretaria de Recursos Humanos, foram acrescentados os resultados da pesquisa feita junto aos servidores no sentido de apreender a percepção dos servidores da Universidade de Brasília sobre a referida política.

\subsection{2 - Objetivo Específico}

- Descrever os diversos programas de capacitação de Recursos Humanos já implementados na Universidade de Brasília, entre o período de 1995 a 2005.

\section{3 - Justificativa}

A sociedade cada vez mais exige uma melhor prestação dos serviços oferecidos pela Universidade. Percebe-se que atualmente a capacitação profissional torna-se uma exigência para que o servidor tenha condições de atender melhor às expectativas de professores, alunos e servidores da Instituição.

Diante desse quadro os profissionais buscam a capacitação profissional no sentido de aperfeiçoar seus conhecimentos e habilidades. A capacitação não só dá condições para o profissional realizar com segurança suas atividades como também 
objetiva preparar o servidor para o exercício suas atribuições, uma vez que para isso a pessoa deverá estar pronta, com hábitos e atitudes condizentes às exigências do seu cargo.

Esse estoque de conhecimento adquirido pelos profissionais, quando organizado, nutrido e gerenciado adequadamente, transforma a empresa numa organização que aprende. Ou seja, numa "organização capacitada na criação, aquisição e transferência de conhecimento, e na modificação de seu comportamento para refletir novos conhecimentos e novos discernimentos" (GARVIN, 1992, p.80).

No caso específico dos servidores da Universidade de Brasília foi analisado a atual política de capacitação de recursos humanos - Programa de Capacitação Profissional (PROCAP) - do ponto de vista de impacto dessa iniciativa em termos da formação profissional, da racionalização do trabalho e da progressão funcional dos servidores que se beneficiaram com a referida política.

Ainda com relação à Universidade de Brasília, o Programa de Capacitação da Secretaria de Recursos Humanos da Universidade de Brasília tem por missão a atualização dos Recursos Humanos desta Instituição, visando à qualidade dos seus serviços, tendo por princípios a melhoria da qualidade de vida e da qualificação profissional; a adequação do perfil de servidores e colaboradores aos diversos ambientes organizacionais; a valorização da sua participação nos programas desta Universidade intensificando, dessa forma, o processo contínuo de treinamento como agente motivador de participação.

Com esse objetivo, o atual programa de capacitação de Recursos Humanos da Universidade de Brasília, disponibilizou só para o ano de 2008 , cerca de $R \$ 450.000,00$ (quatrocentos e cinqüenta mil reais) o que representa $0,065 \%$ do orçamento geral da Universidade.

Tendo em vista a importância desse volume de recursos empregado na formação desses servidores, faz-se necessário fazer uma avaliação sobre o impacto de tal iniciativa na vida profissional dos servidores. 
Em levantamentos anteriores realizados pela Universidade de Brasília (ano 1995 à 2005) foram avaliados 384 cursos diversificados oferecidos pelo Programa de Capacitação, bem como 17.558 servidores que foram beneficiados com tal programa. ${ }^{2}$

Ao iniciar a nossa análise sobre a política de formação de Recursos Humanos, a pesquisa visa contribuir como subsídio complementar no sentido de ampliar o debate e ao mesmo tempo fornecer eventuais subsídios para o aperfeiçoamento da referida política.

\subsection{Desenvolvimento da pesquisa}

Na introdução e primeiro capítulo do trabalho, o leitor encontrará um resumo de como se desenvolveu a pesquisa, sobretudo no que concerne a sua contextualização, problemática, objetivos, metodologia, bem como os resultados gerais do trabalho.

O segundo capítulo, consiste no detalhamento da metodologia utilizada para proceder à análise da atual política de capacitação de Recursos Humanos e da percepção dos servidores da referida política em termos da sua formação profissional, da racionalização do trabalho e progressão funcional de seus servidores.

No terceiro capitulo, sob forma de um referencial teórico, foi feito uma revisão bibliográfica destacando as variadas abordagens sobre a temática geral do nosso trabalho. São elas: formação profissional, racionalização do trabalho e progressão funcional.

No quarto capítulo, a pesquisa expõe a visão dos servidores sobre os cursos do PROCAP, e também indica algumas sugestões no sentido de ampliar o debate e aperfeiçoar a política de capacitação de Recursos Humanos da Universidade de Brasília.

O quinto capítulo apresenta demonstrativos sobre os cursos realizados pelo PROCAP entre o período de 1995 a 2005.

Finalmente, o sexto e último capítulo, a título de considerações finais, evidencia o que a pesquisa nos deu a oportunidade de analisar e refletir, diz como foi feito a pesquisa e conclui as informações obtidas sobre o PROCAP.

\footnotetext{
${ }^{2}$ Informações recolhida nos Anuários Estatísticos de 1999 a 2006 da Universidade de Brasília.
} 


\section{2 - METODOLOGIA}

\section{1 - Característica da Organização e tipo de Pesquisa}

A pesquisa foi realizada na Universidade de Brasília. O curso avaliado foi o Programa de Capacitação Profissional (PROCAP), tendo em vista sua relevância para qualificação profissional dos servidores da Universidade. Como principal instrumento de pesquisa, Utilizamos questionários com perguntas fechadas tendo em vista uma avaliação quantitativa e qualitativa dos dados.

Segundo Boudon (1989), a analise quantitativa são as que permitem colher, num conjunto de elementos, informações comparáveis entre um elemento e outro que podem ser analisados em um certo número de operações cuja lógica é bem definida. Enquanto a análise qualitativa tem como objeto um número pequeno de casos e que, a despeito da amostra ser reduzida pode-se extrair daí análises e proposições convincentes.

\section{2 - Participantes da Pesquisa.}

A pesquisa foi feita de forma censitária: enviamos o questionário (via e-mail e também por impressos) para todos os servidores que foram beneficiados com os programas de formação de Recursos Humanos do curso do PROCAP .

Foram enviados, dessa forma, 150 formulários sendo que obtivemos um total de 76 servidores que responderam ao questionário.

A população da pesquisa foi constituída no total de 76 servidores da Universidade de Brasília que foram beneficiados com os programas de formação de Recursos Humanos do curso do PROCAP a partir de questionário individual, onde foi coletado, dentre outros, os seguintes aspectos: formação profissional e avanços no processo de racionalização do trabalho dos servidores que se beneficiaram com a referida política. 


\section{3 - Instrumento da Coleta dos Dados.}

Para coletar os dados necessários foram aplicados 150 questionários obtendo um retorno de 76 . O que corresponde a 50,66\% dos questionários a partir da investigação em três blocos distintos de informação.

O primeiro bloco tinha como principal objetivo fazer um perfil do servidor.

O segundo bloco procurou investigar números de cursos já realizados pelos servidores ao longo de sua permanência na Universidade de Brasília.

Finalmente, o terceiro bloco investigou o grau de satisfação dos servidores em relação os cursos oferecidos, desenvolvimento das atividades exercidas, conhecimentos adquiridos, satisfação com o corpo docente, adequação do material financeiro e equipamentos utilizados.

Esses questionários com servidores técnicos administrativos do programas e os documentos referentes a avaliações sobre a política de recursos humanos da Universidade de Brasília, se concretizaram em peças centrais da nossa pesquisa. Esse conjunto de dados foram, dessa forma, analisados com a participação intensiva da orientadora de monografia.

\section{4 - Procedimentos da Coleta de Dados.}

Como se trata de uma pesquisa de coleta de dados foi enviado um universo de 50 questionários por meio de correio eletrônico (e-mail), e mais 100 questionários foram distribuídos pessoalmente nos locais de trabalho por todo o campus, alguns recolhidos em seguida, outros recolhidos posteriormente. Também foi garantido aos participantes, sigilo total e absoluto quanto às informações coletadas, bem como a omissão de nomes dos participantes.

\section{5 - Análise das informações.}

Para consolidar as informações obtidas pelos questionários foi adotado o programa Microsoft Excel e os seguintes critérios. 
Foram adotados questões fechadas, e os dados foram consolidadas através de programas estatísticos que nos permitiram a posição - em termos percentuais - dos servidores a partir dos seguintes pontos considerados centrais da pesquisa: formação profissional, racionalização do trabalho e de progressão funcional dos servidores que se beneficiaram com a referida política. 


\section{3 - REFERÊNCIAL TÓRICO}

Este capítulo faz uma breve revisão bibliográfica das principais abordagens sobre capacitação e treinamento de pessoal tendo como referencial analítico abordagem dos seguintes autores: Abbd, Arroyo, Boog, Boudon, Correia, Fleury, Freitas, Garvin, Pilati, Plantullo, Tamayo e Anuário Estatístico da UnB. O estudo desses autores foram fundamentais para o êxito e desenvolvimento da pesquisa.

\section{1 - Da Capacitação}

Arroyo (1987) aponta a capacitação de recursos humanos e as relações sociais na educação como uma reflexão sobre o peso das relações sociais na educação em qualquer projeto de capacitação de recursos humanos.

Correia (1995), define processo da educação e o processo da capacitação como características e embasamentos distintos: "no processo da educação é utilizada a metodologia do ensino, buscando transformá-lo. Para isso é necessário o aluno possuir a lógica do sujeito (no caso o professor) internalizada em si, a fim de compreendê-lo e de tomar parte no processo".(CORREIA, 1995: 15)

Nesse contexto, o processo educativo pode tanto transformar o aluno em um cidadão capaz de construir uma democracia como formar um ser passivo destinado a concordar inclusive com a ditadura. $O$ fato das intenções do sujeito serem estas ou aquelas dentro do processo, isto é, se vão estar a serviço deste ou daquele modelo pedagógico, não o faz menos sujeito, menos emissor fundamental e controlador das atitudes.

Assim, O fato das intenções serem boas ou ruins não muda, do ponto de vista do processo, a maneira pela qual ocorre o diálogo. Portanto, no processo da educação, a comunicação vai estar sob o domínio do emissor da mensagem, que fará uso das formas para criar a necessidade do conhecimento novo no aluno, a fim de conquistá-lo a participar do processo. 
Assim, processo da capacitação apresenta caminhos diferentes do processo de educação: no processo de capacitação é o objeto que capacita o sujeito. O professor ou instrutor é meio e não agente de comunicação.

Na visão do autor os dois processos, o da educação e o da capacitação - quando andam juntos, ocorrem em momentos distintos, até porque provocam estímulos de forma diferenciada no cérebro. "A capacitação, ao contrario da educação, é fruto do embate entre o sujeito e o objeto. Este é que indicará ao sujeito quais são as necessidades de instrumentos, de habilidades a desenvolver para manejá-lo." (CORREIA, 1995, p. 17).

\section{2 - Treinamento de Pessoal}

Muitas organizações têm feito alto investimento em cursos de capacitação, tendo como objetivo preparar as pessoas, visando o aumento de produtividade nas mais variadas tarefas.

A abordagem de Tamayo (2006) define Treinamento e Desenvolvimento como a aquisição sistemática de conhecimentos capazes de provocar, a curto ou longo prazo, mudança na maneira de ser e de pensar do indivíduo, por meio de novos conceitos, valores ou normas e de novas habilidades.

Segundo Boog (2001) o treinamento de pessoal começa como uma resposta a uma necessidade ou a uma oportunidade em um ambiente organizacional. Estabelecer a importância faz com que o círculo completo do processo seja cumprido, pois enfoca as necessidades, os problemas e as oportunidades que ele originalmente visava a atender.

Define Plantullo, que "treinamento é a busca seqüencial de uma perfeição, de um conhecimento de sorte a se atingir um determinado conjunto de objetivo ou objetivos, conflitantes ou não". Plantullo, 2008:54

Para Quinn (1996 apud PLANTULLO, p.110) os investimentos nas organizações em treinamento, têm sido insuficientes. O autor citado, baseando-se no pressuposto de que esse é um dos mais importantes componentes do capital intelectual nas empresas, (e) aponta quatro níveis de capital intelectual: 
a) Conhecimento cognitivo: trata-se do conhecimento adquirido por intermédio de treinamento e certificações básicas:

b) Habilidades avançadas: capacidade de aplicara as regras de uma disciplina em situações práticas da vida real;

c) Entendimento sistêmico: capacidade de perceber relações de causa e efeito, resolver grandes e complexos problemas, além de utilizar a intuição treinada para antecipar relações sutis e conseqüências inesperadas;

d) Criatividade motivada internamente: capacidade, vontade, motivação e perseverança de indivíduos ou grupos para atingir o sucesso e criar vantagens competitivas por intermédio de inovações constantes, contínuas e crescentes. (QUINN,1996 apud PLANTULLO, 2008:110) .

$\mathrm{Na}$ visão de Abbad, Freitas e Pilati (2006), a necessidade de treinamento são valores de competências ou repertório de conhecimentos, habilidades e atitudes (CHAs) no trabalho. "Avaliações de necessidades objetivam diagnosticar ou prognosticar necessidades de TD\&E, de modo que as mesmas, transformadas em objetivos instrucionais, facilitem o desenho de ações de aprendizagem para atendêlas".(ABBAD, FREITAS E PILATI, 2006:231).

Para Hinrichs "Treinamento pode ser definido como quaisquer procedimentos de iniciativa organizacional, cujo objetivo é ampliar a aprendizagem entre os membros da organização". (HINRICHS, 1976 apud ABBD, 2006, p. 140)

Segundo Pilati (2006), a aprendizagem é fundamental aos servidores de uma organização, bem como treinamento, desenvolvimento e educação (TD\&E) atingindo, assim, seus objetivos de um bom desempenho nas suas funções, como também, as ações de capacitação nas organizações que pretendem influenciar o comportamento humano no ambiente de trabalho.

A partir dessas abordagens, pode-se perceber a importância desses dois parâmetros - Capacitação de Servidores, Treinamento de Pessoal - na condução de qualquer política institucional visando um melhor aperfeiçoamento de seu quadro de servidores. 


\section{A POLÍTICA DE CAPACITAÇÃO: A VISÃO DOS SERVIDORES TÉCNICO- ADMINISTRATIVOS DA UNIVERSIDADE DE BRASÍLIA}

O Programa de Capacitação Profissional (PROCAP) da Universidade de Brasília tem como objetivo, desenvolver atividades de capacitação, visando ao atendimento das reais demandas dos seus servidores.

Para fins deste estudo, foi analisada a política de capacitação da Universidade de Brasília, por meio de questionários, a partir das diferentes visões e percepções dos servidores que tiveram participação em cursos de formação do Programa de Capacitação Profissional (PROCAP) entre o período de 1995 a 2005.

\section{1. O Programa de Capacitação Profissional (PROCAP)}

O Programa de Capacitação Profissional (PROCAP) da Universidade de Brasília foi criado em junho do ano de 1995, e tem por missão a atualização dos Recursos Humanos desta Instituição, visando à qualidade dos seus serviços, e por princípios a melhoria da qualidade de vida e da qualificação profissional; a adequação do perfil de servidores e colaboradores aos diversos ambientes organizacionais; a valorização da sua participação nos programas desta Universidade e o processo contínuo de treinamento como agente motivador de participação.

O objetivo é desenvolver atividades de capacitação, visando ao atendimento das reais demandas do trabalho, às necessidades da UnB e da sociedade. Considera-se o treinamento e a capacitação funcional como processos permanentes e contínuos, que podem tornar-se ferramentas eficazes, dinâmicas e rápidas, como processos educativos por excelência, enquanto facilitadores da aprendizagem, do crescimento e do desenvolvimento psicossocial e intelectual dos servidores. ${ }^{3}$

Entre o período de 1995 a 2005 foram realizados 384 cursos, com a participação de 402 instrutores, e um total de 17. 558 participantes dos cursos do PROCAP.

\footnotetext{
${ }^{3}$ Informações disponíveis na página do PROCAP: www.unb.br/shr/procap
} 


\subsection{A visão dos servidores sobre o PROCAP}

De acordo com os dados do programa, 17.558 certificados já foram expedidos pelo programa de capacitação da Universidade de Brasília, no período de 1995 a 2005. Beneficiam-se do programa Professores, Servidores Técnico-administrativos, prestadores de serviço e em alguns casos o público externo.

Apesar dos dados apresentados apontarem para um sucesso relativo do programa, essa pesquisa tem como objetivo avaliar o PROCAP tendo como público alvo os servidores que tiveram participação em cursos de formação do Programa de Capacitação Profissional.

A pesquisa teve como principal instrumento analítico a aplicação de 150 questionários com técnicos especialistas em capacitação da Universidade de Brasília.

Os questionários aplicados foram destinados aos servidor-técnicos concluintes de cursos realizados pelo Programa de Capacitação Profissional (PROCAP) da Universidade de Brasília com a finalidade de analisar a percepção dos servidores quanto à política de capacitação de recursos humanos da Universidade de Brasília.

Além dos dados pessoais, foram analisados as seguintes variáveis: formação profissional, racionalização do trabalho daqueles que se beneficiaram da referida política. De uma forma geral, o questionário contempla questões sobre o perfil do servidor como, faixa etária, sexo, escolaridade, situação funcional, opiniões específica ao PROCAP e grau de satisfação. 


\subsubsection{Dados pessoais}

\subsubsection{1 - Perfil do servidor}

\section{FIGURA 1: Faixa Etária}

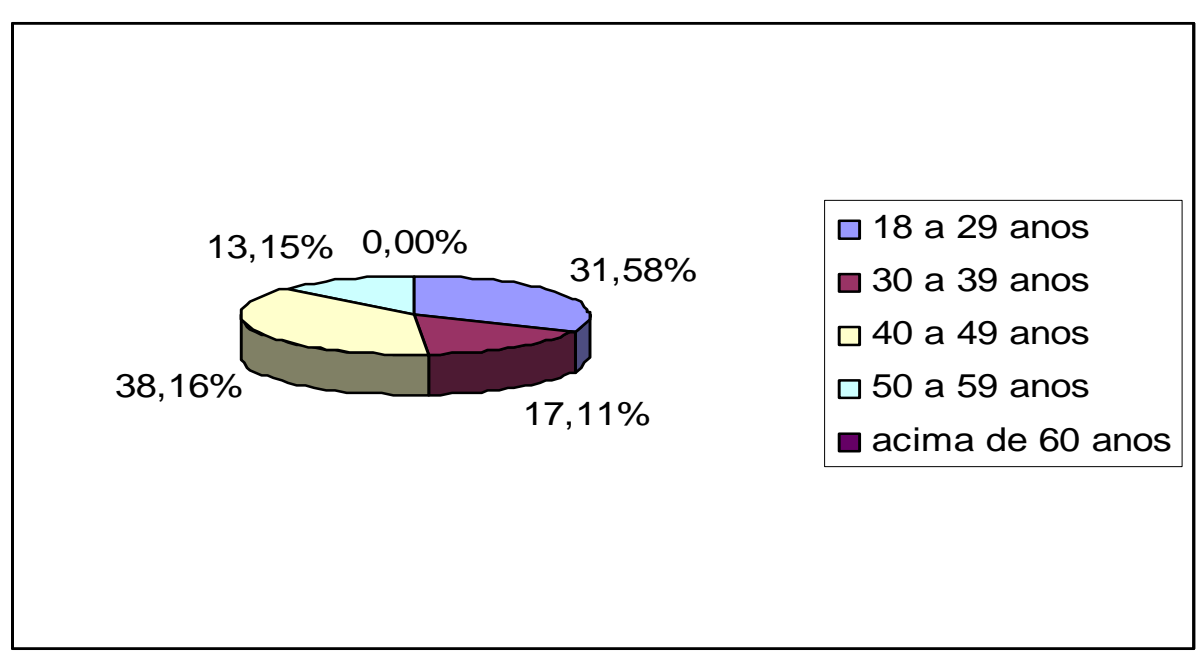

Fonte: elaborada pela autora

Em referência à faixa etária dos participantes da pesquisa, podemos observar que $38,16 \%$ dos servidores se encontra entre 40 e 49 anos, o que representa a faixa etária da maioria. A segunda faixa em ordem de grandeza corresponde a $(31,58 \%)$ onde se situa os servidores entre 18 e 29 anos e a menor faixa de idade se situa em torno de (13,15\%) que corresponde a faixa etária de 50 a 59 anos.

\section{FIGURA 2: Sexo.}

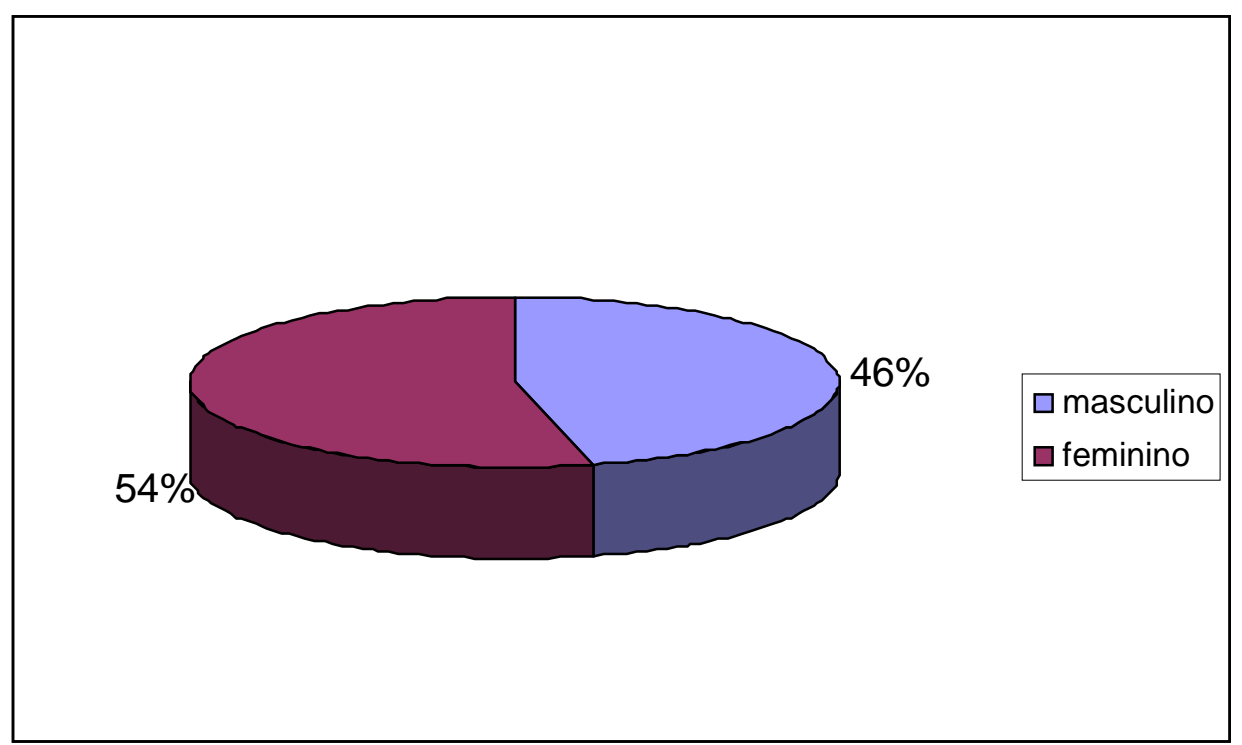

Fonte: elaborada pela autora 
A figura 2 retrata que o percentual, por sexo, dos participantes da pesquisa apresenta uma distribuição uniforme entre o sexo feminino (54\%) e (46\%) para o sexo masculino.

\section{FIGURA 3: Nível de Escolaridade.}

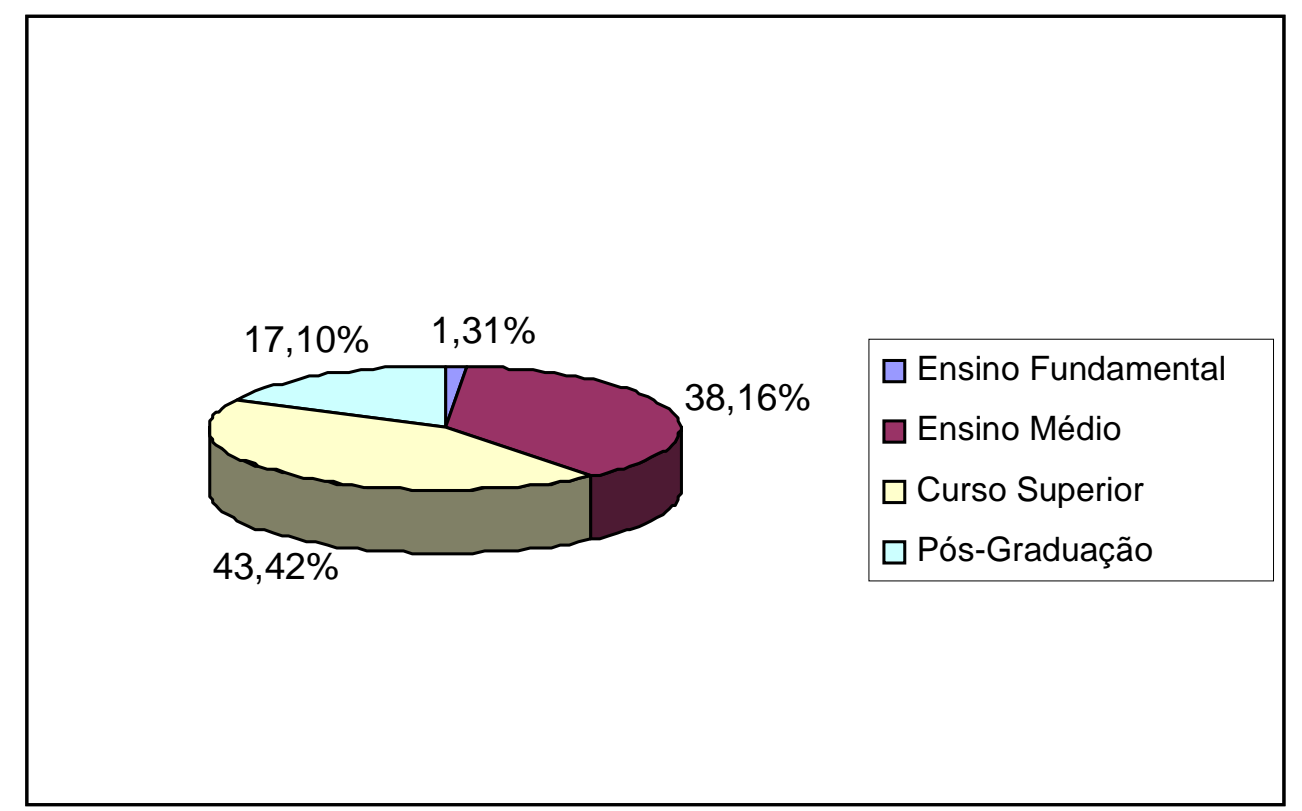

Fonte: elaborada pela autora

A figura 3 retrata que o percentual de escolaridade dos participantes da pesquisa apresenta uma certa distribuição uniforme entre os portadores de curso superior $43,42 \%$ e os participantes que possuem curso de ensino médio $(38,16 \%)$. 
FIGURA 4: Situação Funcional

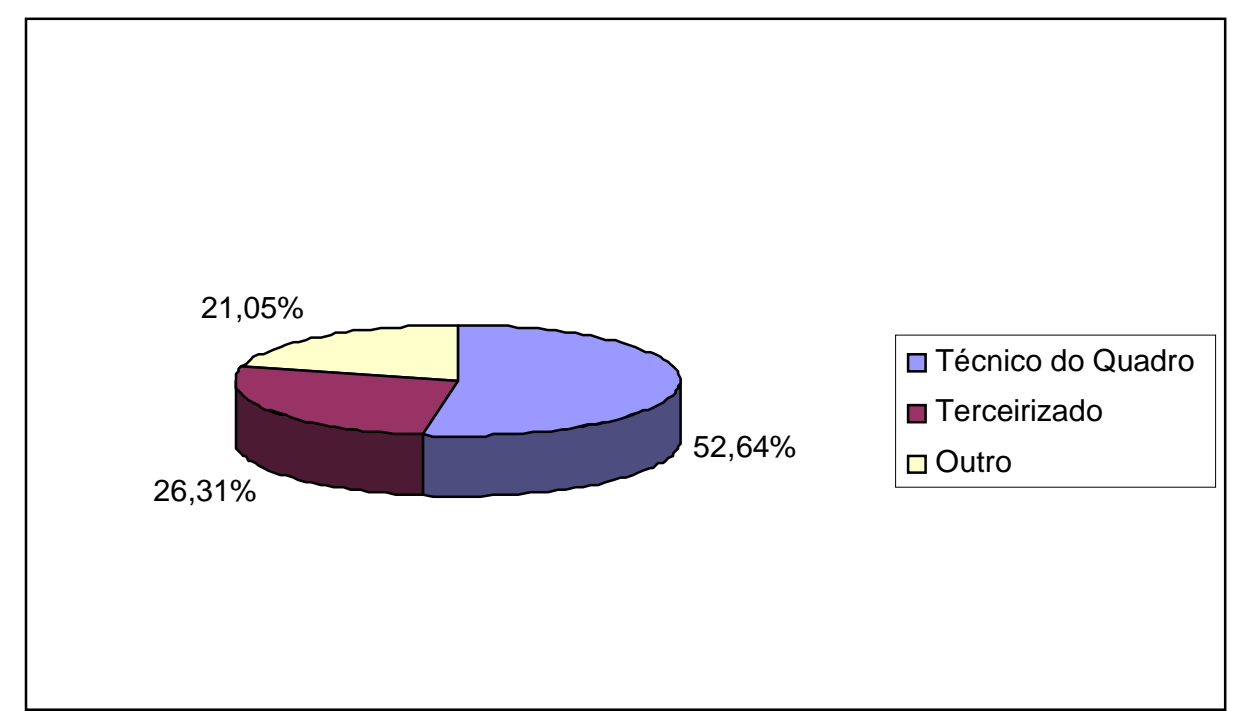

Fonte: elaborada pela autora

O percentual de $(52,64 \%)$ dos servidores técnicos do quadro, nos traz uma realidade do que realmente a Universidade está vivenciando hoje, ou seja, quase a metade dos servidores são terceirizados e estagiários.

\subsubsection{2 - Participação no PROCAP}

FIGURA 5: Servidores que participaram do curso do PROCAP.

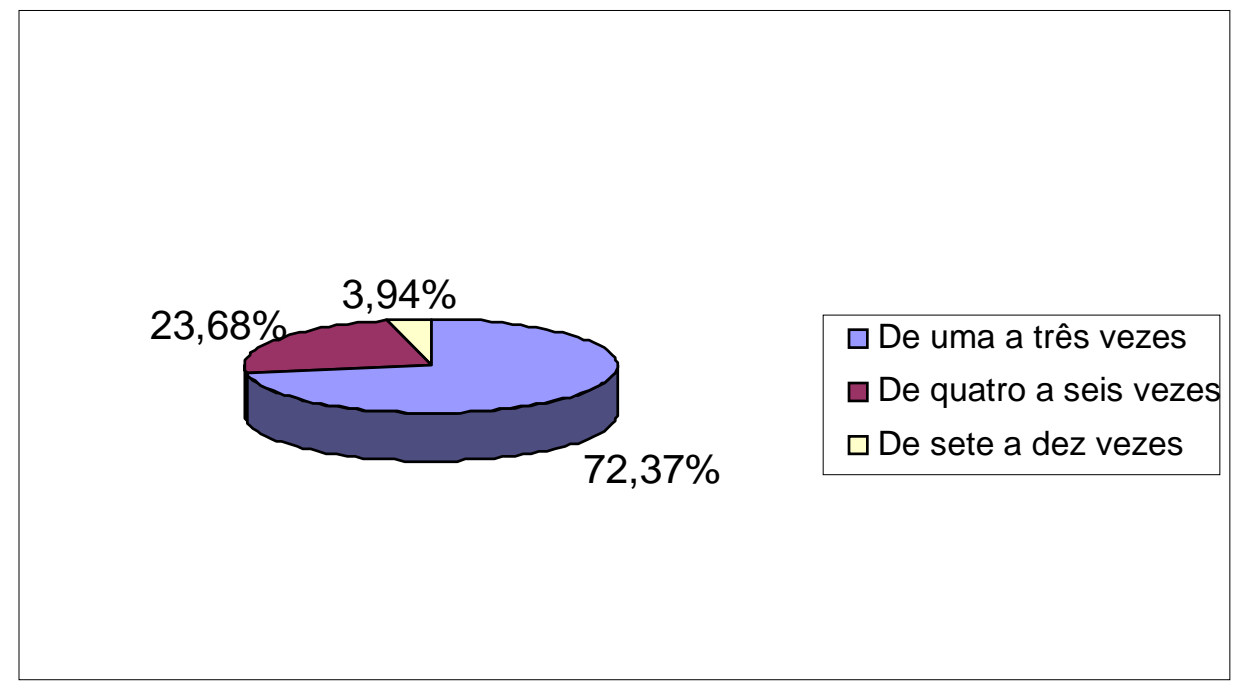

Fonte: elaborada pela autora

A figura 5 retrata que a relação entre a quantidade de participantes da pesquisa e o número de vezes que fizeram o curso é inversamente proporcional, ou seja, quanto 
maior o número de vezes de realização do curso, menor é o número de participantes. Esta análise permite evidenciar que os servidores, em sua maioria, fizeram o curso por no máximo três vezes, muitos por falta de adequação, conforme demonstração nas figuras 6,11 e 12 .

FIGURA 6: Servidores que tiveram problema de liberação do seu expediente de trabalho para realização do curso do PROCAP.

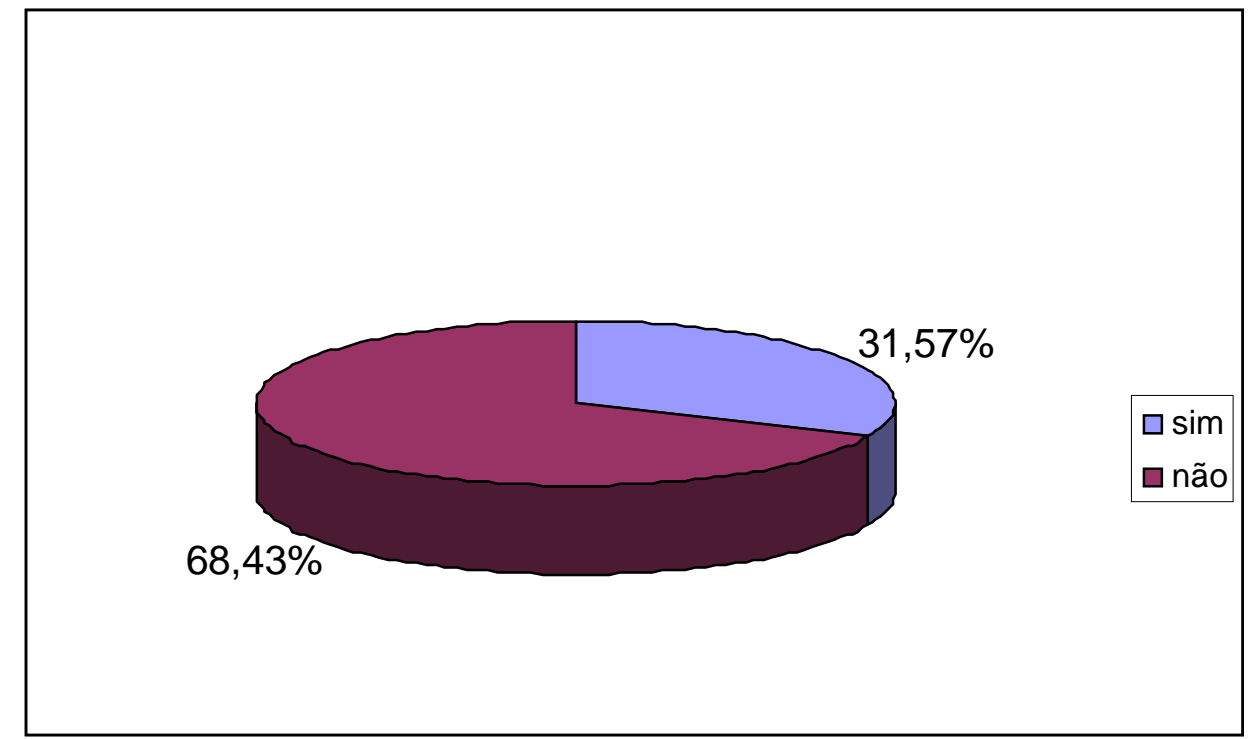

Fonte: elaborada pela autora

Percebe-se que é bem elevado o percentual $(68,43 \%)$ de servidores que não tiveram problema de liberação do seu expediente de trabalho para realização do curso. Entretanto, o percentual de $(31,57 \%)$ de servidores que tiveram o referido problema ainda é preocupante. Assim, se por um lado a UnB disponibiliza várias opções de cursos, sem nenhum custo adicional, visando à qualidade dos seus serviços, o aperfeiçoamento de desempenho, o aumento de produtividade, a melhoria da qualidade de vida, da qualificação profissional e das relações interpessoais, por outro lado, os funcionários não conseguem participar dos cursos devido não serem liberados do expediente pela chefia imediata, por motivos diversos. 
4.2.1.3 - Grau de satisfação dos servidores em relação ao PROCAP FIGURA 7: Relação entre o PROCAP e aumento na cultura geral do servidor

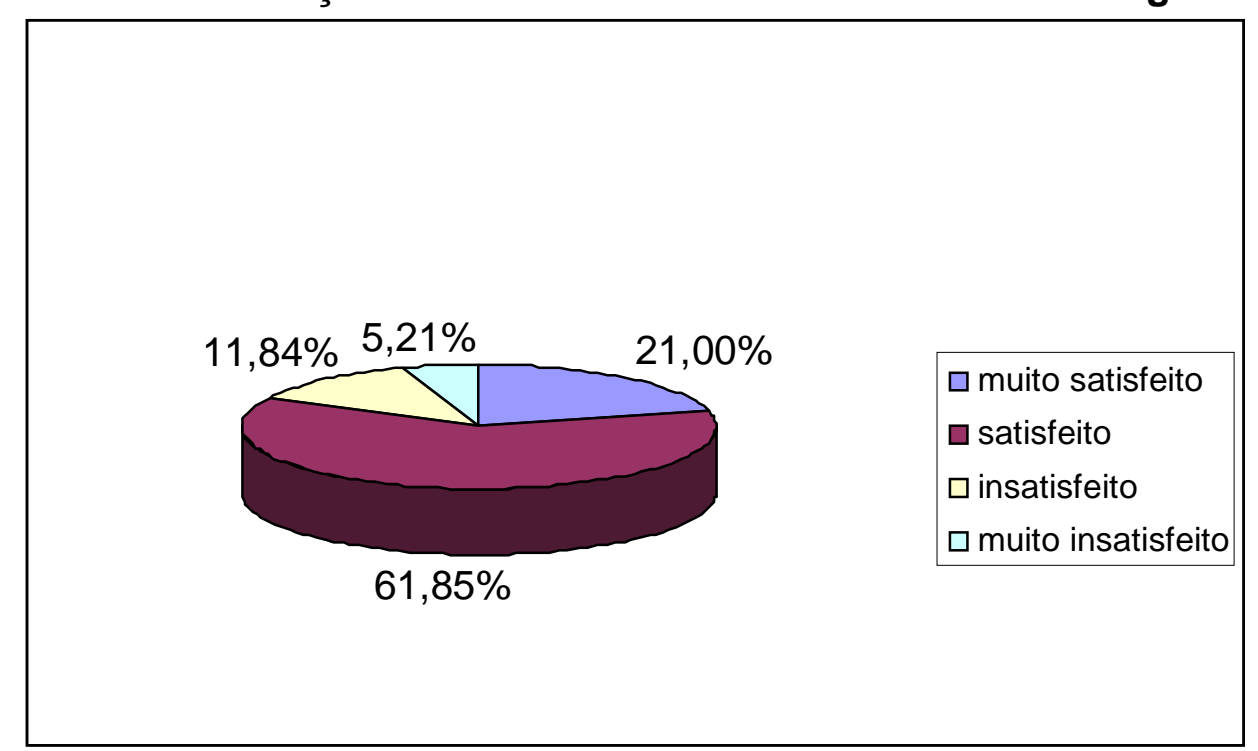

Fonte: elaborada pela autora

A figura 7 indica que a maioria dos servidores $(61,85 \%)$ que tiveram acesso ao PROCAP estimam uma melhora substantiva em sua cultura geral. Apenas (5,26\%) se mostraram muito insatisfeitos. Esse é um dado que pode indicar os cursos de formação do PROCAP objetivam não somente oferecer uma formação pontual, dirigida à rotina de trabalho, mas também a um acréscimo no nível de informação geral - cultural e científica - do servidor. 
FIGURA 8: O PROCAP como condutor de atualização sobre as principais abordagens do mundo do trabalho (relação pessoal, clareza nas decisões, uso de novas tecnologias).

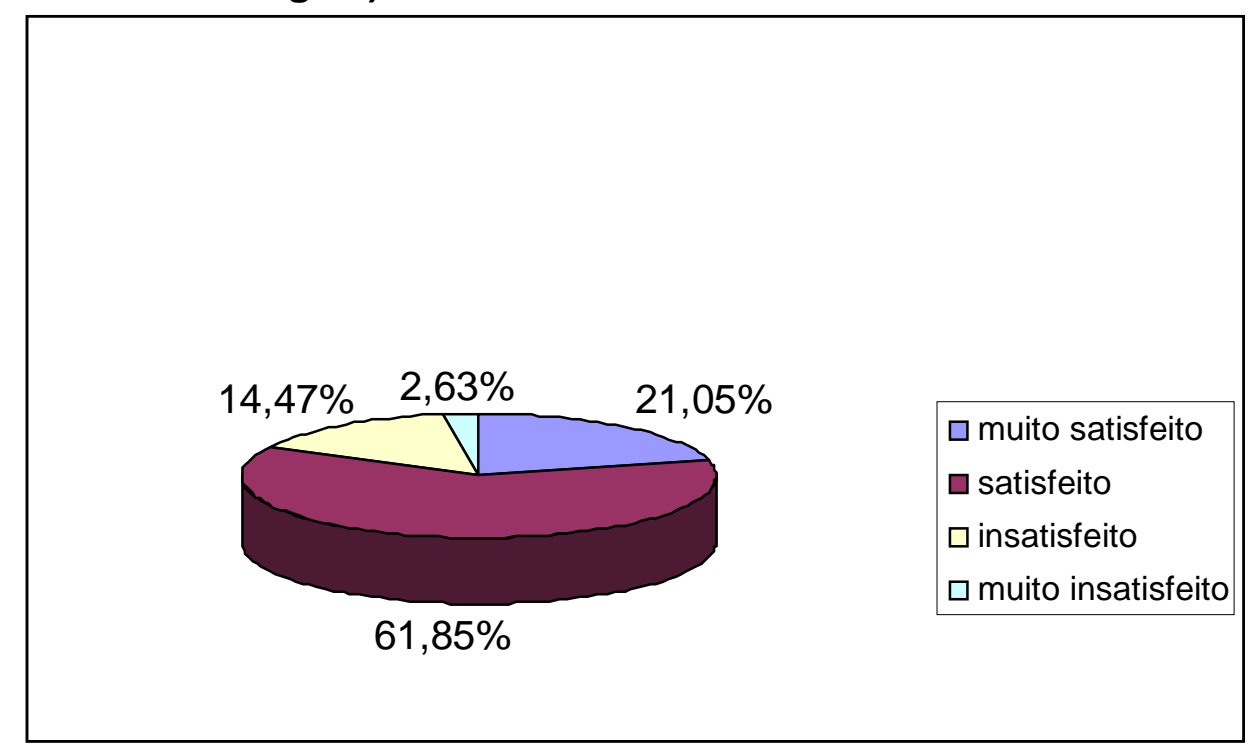

Fonte: elaborado pela autora

Na figura 8, $(61,85 \%)$ demonstram ter conhecimento dessas novas abordagens. O que significaria que a maioria dos servidores sai do curso com uma visão panorâmica sobre as principais abordagens do mundo do trabalho. O que é um indicador bastante positivo gerado a partir desses cursos.

FIGURA 9: Conteúdo oferecido pelo PROCAP e o desenvolvimento das atividades exercidas na Universidade de Brasília.

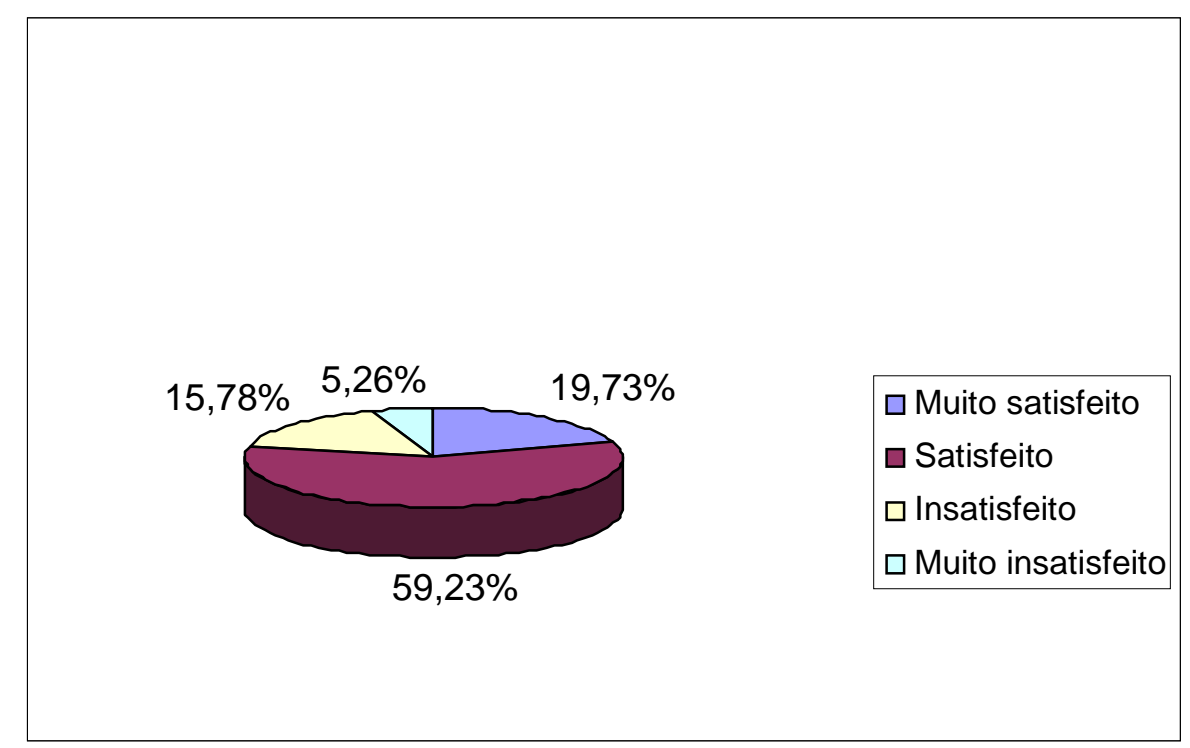

Fonte: elaborado pela autora 
Na figura 9, retrata uma satisfação de $(59,23 \%)$ e muito satisfeito de $(19,73 \%)$ o que demonstra uma interação mais ou menos equilibrada entre o conteúdo oferecido com suas atividades exercidas no trabalho. Somente $(5,26 \%)$ estão muito insatisfeitos e $(15,78 \%)$ insatisfeitos, estima à figura. $O$ que demonstra que nesse aspecto 0 PROCAP tem conseguido fornecer uma formação profissional condizente com as obrigações e responsabilidades dos servidores da Universidade de Brasília.

FIGURA 10: aplicação do conhecimento adquirido durante o curso no seu trabalho diário.

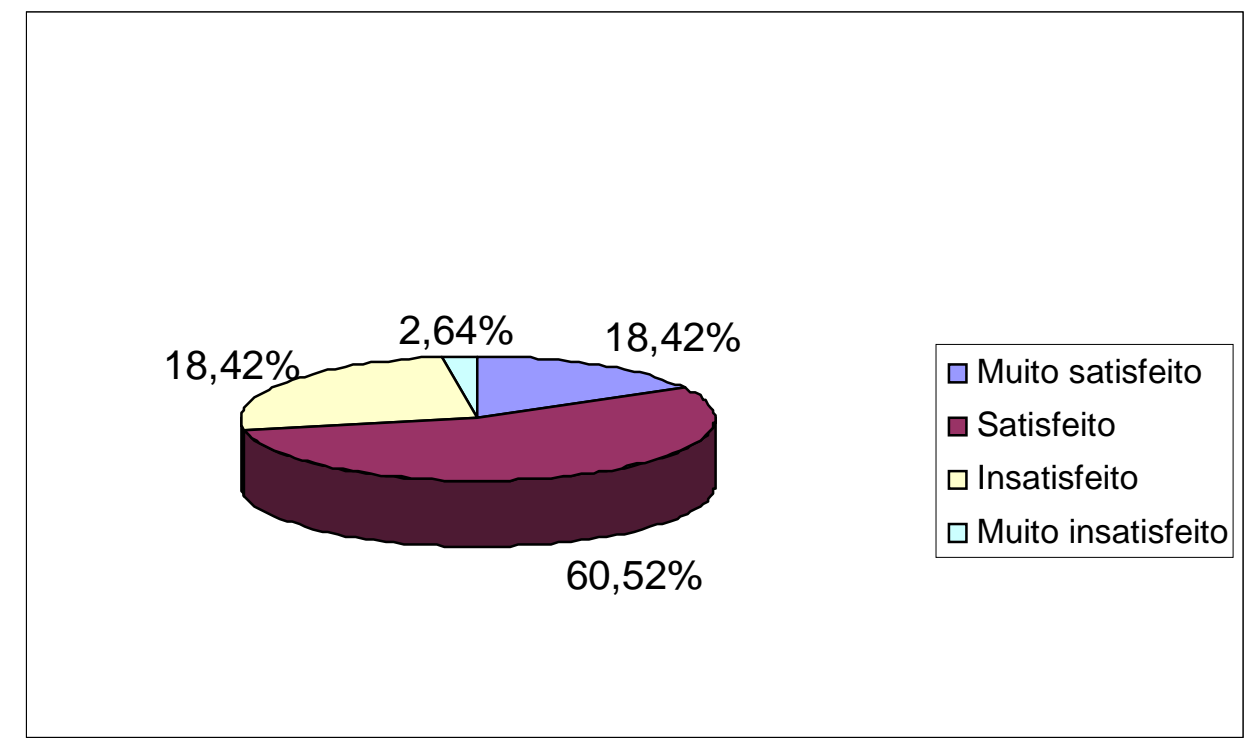

Fonte: elaborado pela autora

Essa questão tinha como objetivo principal analisar o conhecimento adquiridos pelos participantes. Os resultados da pesquisa indicaram que $(60,52 \%)$ consideram satisfeitos e $(18,42 \%)$ muito satisfeito, que é possível aplicar o conhecimento adquirido durante o curso no seu trabalho diário. Isso poderá ser lido como ponto positivo para uma instituição. 
FIGURA 11: Qualificação do corpo docente do PROCAP.

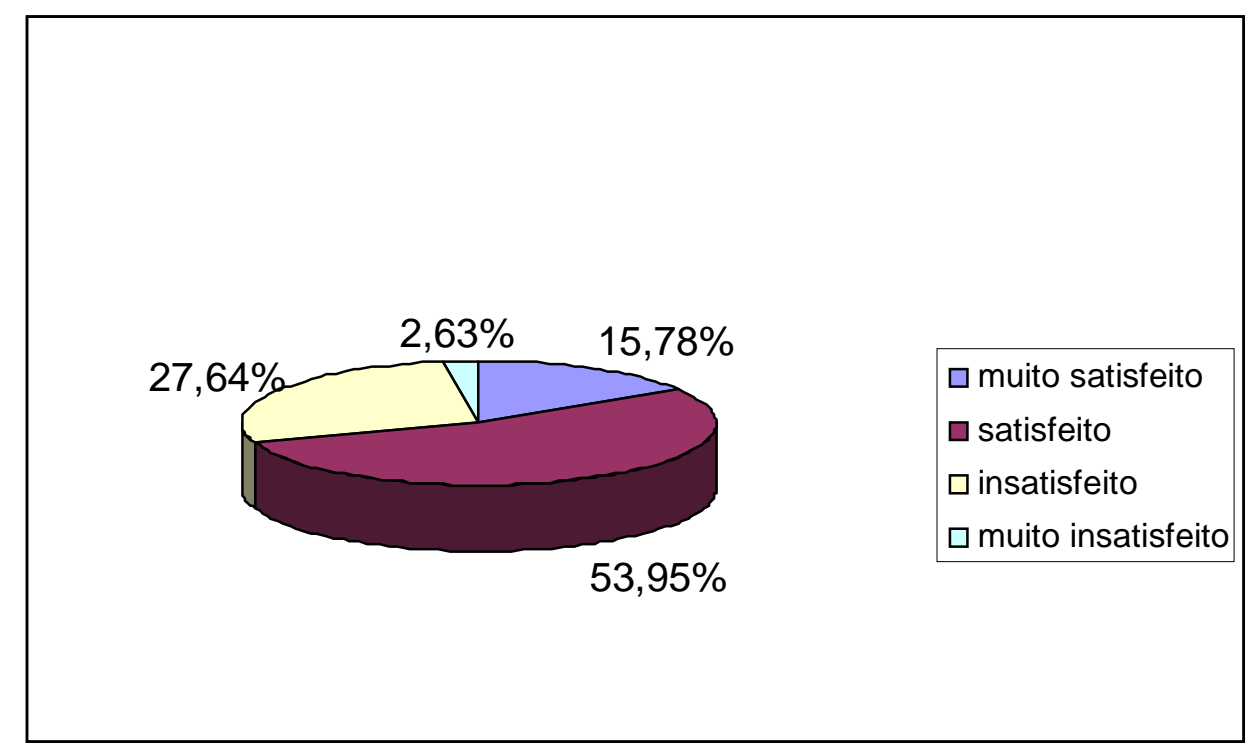

Fonte: elaborado pela autora

Na visão dos servidores, o corpo docente do PROCAP demonstra $(53,95 \%)$ de satisfeito e (15,78\%) de muito satisfeito, tal percentual elevado demonstra que nesse aspecto o PROCAP tem conseguido uma equipe de professores que atinge as metas gerais do programa. Porém é notável que muitos servidores não aprovem o corpo docente, $(27,64 \%)$ insatisfeito e $(2,63 \%)$ muito insatisfeito, que é considerado um número elevado. 
FIGURA 12: Recursos fornecidos pelo PROCAP (sala de aula, equipamento, luminosidade, sanitário, bebedouro e cantina).

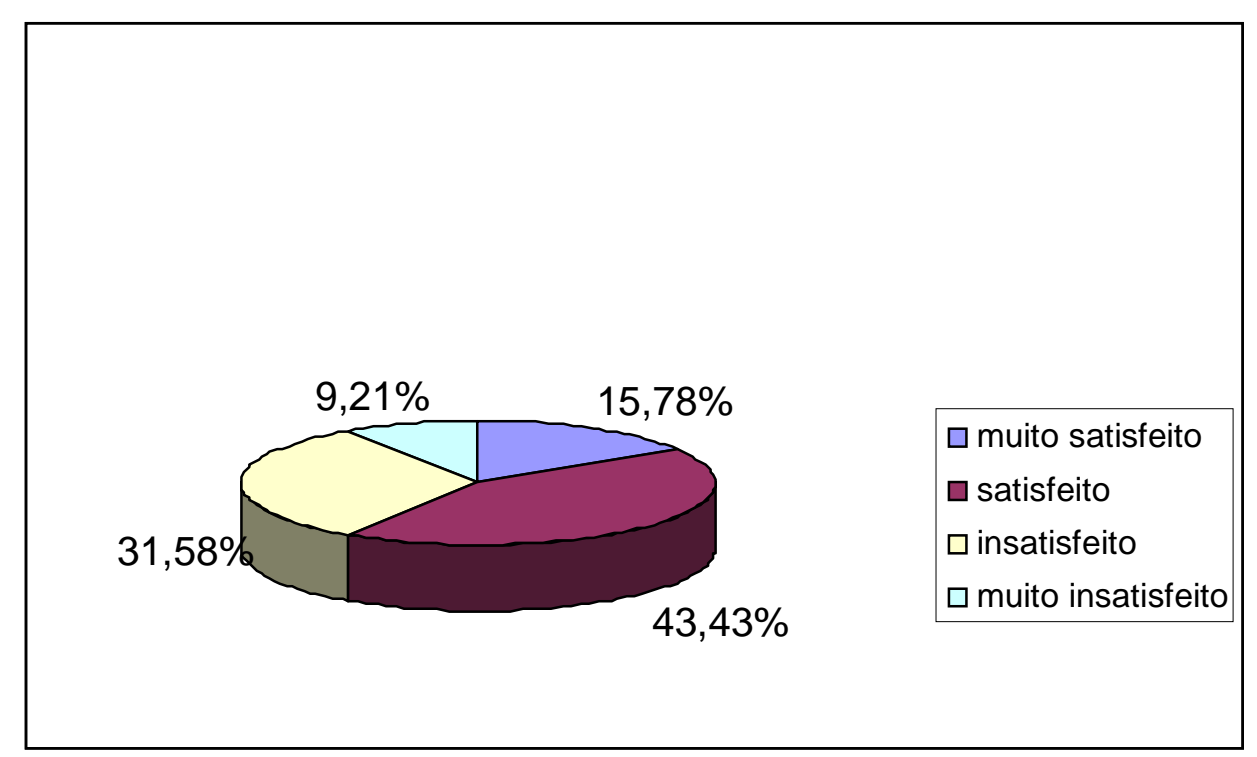

Fonte: elaborado pela autora

O conceito dado pelos concluintes aos cursos do PROCAP, indica que $(43,43 \%)$ estão satisfeito e $(15,78 \%)$ muito satisfeito com os recursos fornecidos pelo PROCAP. Entretanto, é também expressivo o percentual de servidores que reclama dos recursos oferecidos pela Universidade, $(31,58 \%)$ estão insatisfeitos e $(9,21 \%)$ muito insatisfeito. 


\section{5 - DEMONSTRATIVOS DOS CURSOS RELIZADOS PELO PROCAP}

Os dados e informações apresentados nas tabelas abaixo foram obtidos através de consultas publicadas aos volumes de Anuários Estatísticos, entre o período de 1995 a 2005, organizados pela Secretaria de Planejamento da Universidade de Brasília, que se iniciou em 1998. Cada anuário apresenta dados referentes ao ano anterior. A última publicação foi do ano de 2006, referente ao ano anterior, por essa razão, não informamos dados entre os anos 2006 a 2008.

Tabela 1 - Evolução do Número de Atividades de Capacitação de Pessoal

\begin{tabular}{l|r|r|r}
\hline \multicolumn{1}{c|}{ Ano } & \multicolumn{1}{|c|}{ Cursos } & \multicolumn{1}{c}{ Instrutores } & \multicolumn{1}{c}{ Participantes } \\
\hline 1995 & 31 & 31 & 437 \\
\hline 1996 & 45 & 45 & 329 \\
\hline 1997 & 20 & 20 & 300 \\
\hline 1998 & 18 & 19 & 798 \\
\hline 1999 & 58 & 60 & 2.508 \\
\hline 2000 & 27 & 39 & 1.843 \\
\hline 2001 & 22 & 24 & 747 \\
\hline 2002 & 22 & 25 & 1.345 \\
\hline 2003 & 48 & 39 & 2.241 \\
\hline 2004 & 45 & 48 & 4.381 \\
\hline 2005 & 48 & 52 & 2.638 \\
\hline Total & $\mathbf{3 8 4}$ & $\mathbf{4 0 2}$ & $\mathbf{1 7 . 5 5 8}$ \\
\hline Fot & & & \\
\hline
\end{tabular}

Fonte: elaborada pela autora

De acordo com os dados do programa, 17.558 certificados já foram expedidos pelo programa de capacitação da Universidade de Brasília, no período de 1995 a 2005. Beneficiam-se do programa Professores, Servidores Técnico-administrativos, prestadores de serviço e em alguns casos o público externo.

Observa-se que os números de cursos, instrutores e participantes não obedece a um padrão regular no decorrer dos anos, visto que a tabela apresenta aumentos e quedas, principalmente no que tange aos participantes. Podemos atribuir essa variação

\footnotetext{
${ }^{4}$ Informações recolhida nos Anuários Estatísticos de 1999 a 2006 da Universidade de Brasília.
} 
as greves dos professores e técnico-administrativo, nos anos de 1998 e 2001, ocorridas na universidade. Sendo assim, o aumento mais considerável foi o que aconteceu entre 1998 e 1999 e a queda a que aconteceu entre 2000 e 2001.

Apesar das quedas evidenciadas, o número de participantes é alto, pois no espaço amostra evidenciado na tabela, inferimos uma média de 1.596 participantes por ano.

Nas tabelas abaixo, relatam a situação da Universidade entre os anos de 2002 a 2005, em relação aos afastamentos de técnicos para capacitação, tanto no país como no exterior.

Segundo a Resolução de $n^{\circ}$ 003/2002, do Conselho de Administração da UnB, determina que a licença de capacitação é concedida ao servidor após cada qüinqüênio de efetivo exercício, a fim de que o mesmo possa afasta-se do exercício do cargo efetivo, com a respectiva remuneração, por até três meses, para participar de eventos de capacitação que contribuam para o desenvolvimento do servidor e que atendam aos interesses da Instituição.

Tabela 2 - Relação de Afastamento de Técnicos para Capacitação - 2002

\begin{tabular}{|l|c|c|c|c|c|c|}
\hline \multirow{2}{*}{ Motivo } & \multicolumn{3}{|c|}{ Com Vencimento } & \multicolumn{3}{c|}{ Sem Vencimento } \\
\cline { 2 - 8 } & Na IES & No País & No Exterior & Na IES & No País & No Exterior \\
\hline Superior & - & 5 & - & 1 & - & - \\
\hline Intermediário & - & 2 & - & - & - & - \\
\hline Apoio & - & - & - & - & - & - \\
\hline
\end{tabular}

Fonte: SRH, Apud Anuário

Tabela 3 - Relação de Afastamento de Técnicos para Capacitação - 2003

\begin{tabular}{|l|c|c|c|c|c|c|}
\hline \multirow{2}{*}{ Motivo } & \multicolumn{3}{|c|}{ Com Vencimento } & \multicolumn{3}{c|}{ Sem Vencimento } \\
\cline { 2 - 7 } & Na IES & No País & No Exterior & Na IES & No País & No Exterior \\
\hline Superior & - & 9 & 5 & 1 & - & - \\
\hline Intermediário & - & - & - & - & - & - \\
\hline Apoio & - & - & - & - & - & - \\
\hline
\end{tabular}

Fonte: SRH, Apud Anuário 
Tabela 4 - Relação de Afastamento de Técnicos para Capacitação - 2004

\begin{tabular}{|l|c|c|c|c|c|c|}
\hline \multirow{2}{*}{ Motivo } & \multicolumn{3}{|c|}{ Com Vencimento } & \multicolumn{3}{c|}{ Sem Vencimento } \\
\cline { 2 - 8 } & Na IES & No País & No Exterior & Na IES & No País & No Exterior \\
\hline Superior & - & 7 & 2 & 1 & - & - \\
\hline Intermediário & - & - & 1 & - & - & - \\
\hline Apoio & - & - & - & - & - & - \\
\hline
\end{tabular}

Fonte: SRH, Apud Anuário

Tabela 5 - Relação de Afastamento de Técnicos para Capacitação - 2005

\begin{tabular}{|l|c|c|c|c|c|c|}
\hline \multirow{2}{*}{ Motivo } & \multicolumn{3}{|c|}{ Com Vencimento } & \multicolumn{3}{c|}{ Sem Vencimento } \\
\cline { 2 - 7 } & Na IES & No País & No Exterior & Na IES & No País & No Exterior \\
\hline Superior & - & 24 & 4 & - & - & - \\
\hline Intermediário & - & - & - & - & - & - \\
\hline Apoio & - & - & - & - & - & - \\
\hline
\end{tabular}

Fonte: SRH, Apud Anuário

O afastamento do servidor técnico-administrativo para capacitação é caracterizado como dispensa temporária do exercício integral ou parcial das atividades de seu cargo para participar de diferentes modalidades de formação, atualização e aperfeiçoamento profissional. Após o término do afastamento, é necessário contribuição do servidor, utilizando do seu conhecimento adquirido com a capacitação, para a melhoria de sua eficiência e da qualidade dos serviços prestados.

Tabela 6 - Programa Quartas Gerenciais - 1999-2003

\begin{tabular}{c|c|r}
\hline Ano & Palestras & \multicolumn{2}{c}{ Participantes } \\
\hline 1995 & 29 & 1.603 \\
\hline 1996 & 25 & 1.318 \\
\hline 1997 & 17 & 1.784 \\
\hline $1998\left(^{*}\right)$ & 13 & 816 \\
\hline 1999 & 17 & 1.035 \\
\hline 2000 & 16 & 1.068 \\
\hline 2001 & 15 & 755 \\
\hline 2002 & 14 & 1.154 \\
\hline 2003 & 14 & 829 \\
\hline Total & $\mathbf{1 6 0}$ & $\mathbf{1 0 . 3 6 2}$ \\
\hline
\end{tabular}

Fonte: SRH, Apud Anuário

* PROCAP/SRH. Em 1998, não houve a programação dos meses de marcos/abril em virtude das obras de recuperação/reforma do Auditório da Reitoria. 
Em 1995 foi originado as Quartas Gerenciais como um projeto especial, que chegou a finalizar em 2003, completando apenas 9 anos de efetivo exercício, que teve como objetivo atualizar e desenvolver, prioritariamente, o corpo gerencial da UnB. Contudo, foi um evento realizado nas quartas-feiras, aberto a todos os demais servidores docentes e técnico-administrativos, alunos e representantes de outras instituições públicas e privadas e da comunidade externa. Foram palestras proferidas por profissionais altamente capacitados, contemplando temas relacionados ao papel do gerente, vistos sob enfoques atuais.

O Programa de preparação para educação básica é também uma preocupara da Universidade com os seus servidores.

Tabela 7 - Programa de Preparação para Educação Básica - 1999-2005

\begin{tabular}{r|c|r}
\hline Ano & Palestrantes & \multicolumn{2}{|c}{ Participantes } \\
\hline 1999 & 19 & 327 \\
\hline 2000 & 19 & 421 \\
\hline 2001 & 13 & 209 \\
\hline 2002 & 13 & 214 \\
\hline 2003 & 13 & 299 \\
\hline 2004 & 9 & 160 \\
\hline 2005 & 10 & 210 \\
\hline Total & 96 & $\mathbf{1 . 8 4 0}$ \\
\hline
\end{tabular}

Fonte: elaborada pela autora ${ }^{5}$

O programa de preparação para educação básica visa alfabetizar os servidores da Universidade. Além disso, prepara os servidores já alfabetizados para realizar a prova que dá o direito ao certificado de conclusão da educação básica (antiga quarta série fundamental).

Observa-se que o número de participantes de preparação para educação básica é oscilante, pois não mantém um padrão regular no decorrer dos anos. Sendo assim, ocorrem períodos de estabilidades, quedas bruscas e aumentos.

Por outro lado, quanto ao número de professores, observa-se que é sempre decrescente, com exceção de 2005 que teve um aumento irrelevante, o que, por sua vez, dá margem para questionar os incentivos que mantêm os professores no programa.

\footnotetext{
${ }^{5}$ Informações recolhida nos Anuários Estatísticos de 1999 a 2006 da Universidade de Brasília.
} 


\section{6 - CONSIDERAÇÕES FINAIS}

Esta pesquisa nos deu a oportunidade de analisar e refletir sobre os diversos cursos de Capacitação Profissional da Universidade de Brasília a partir das diferentes visões e percepções dos servidores que tiveram participação em cursos de formação no Programa de Capacitação Profissional (PROCAP) entre o período de 1995 a 2005.

Para atingir o objetivo acima mencionado foram aplicados questionários aos servidores da Universidade de Brasília para coletar dados necessários a partir do perfil dos servidores até o grau de satisfação em relação aos cursos do PROCAP. Inicialmente, utilizou-se a técnica de enviar os questionários por meio eletrônico (email), contudo, a resposta não foi muito satisfatória, poucos atentaram para a solicitação. A segunda opção foi distribuir pessoalmente nos locais de trabalho por todo o campus, alguns recolhidos em seguida, outros recolhidos posteriormente.

Durante as visitas aos setores foi feita uma observação muito importante: a carência de servidores por toda a Universidade; alguns deles, novatos, ou seja, não haviam feito nenhum tipo de cursos do PROCAP, outros com mais tempo de casa, porém, não tinham com quem revezar suas atividades de trabalho para fazer o curso. Apesar disso, no geral os servidores recebiam de forma receptiva os questionários o que facilitou muito no desenvolvimento do trabalho.

Posteriormente, foram consolidadas as informações obtidas pelos questionários e se verificou que o conceito dado pelos concluintes aos cursos do PROCAP identificou que a maioria está satisfeita, ainda que exista também com um grau muito elevado de insatisfação.

O questionário aplicado aos servidores da Universidade de Brasília contempla questões sobre o perfil do servidor como faixa etária, sexo, nível de escolaridade e situação funcional, também aborda a participação deles nos cursos do PROCAP demonstrando as opiniões dos mesmos quanto ao referido curso e demonstra o grau de satisfação dos participantes após a conclusão do treinamento.

Em referência ao perfil dos participantes se constata que a faixa etária da maioria $(38,16 \%)$ dos participantes da pesquisa se encontra entre 40 e 49 anos. Por sexo, o percentual afirma uma distribuição uniforme de $54 \%$ para o sexo feminino e $46 \%$ para o 
sexo masculino. No que diz respeito à escolaridade, o que predominou foi o nível superior com 43,42\%, e em segundo lugar, por ordem de grandeza, o ensino médio com 38,16\%. Já no que tange à situação funcional dos participantes, o percentual de $52,64 \%$ dos servidores técnicos do quadro nos traz uma realidade do que a Universidade está vivenciando hoje - ou seja, quase a metade dos servidores são terceirizados ou estagiários.

Em relação à participação dos servidores nos cursos do PROCAP, a pesquisa mostra que a maioria (72,37\%) realizou cursos de uma a três vezes, com a evidência que muitos servidores (31,57\%) são impedidos da liberação do seu expediente de trabalho para realização do curso, embora sabendo que a instituição forneça o curso para o aperfeiçoamento do próprio servidor que, por sua vez, trará retorno as suas atividades diárias de trabalho.

Em se tratando do grau de satisfação com relação os cursos do PROCAP, a pesquisa constatou que o referido curso proporciona não só retorno quanto ao trabalho, mas também quanto à vida pessoal do servidor, visto que $61,85 \%$ dos participantes estão satisfeitos com o aumento da cultura geral que adquiriram após a conclusão do curso, constatou também que após o curso os servidores saem com uma visão panorâmica sobre as principais abordagens do mundo do trabalho, melhorando, portanto, as suas relações pessoais, as clarezas nas decisões e uso de novas tecnologias que necessitam de dominar.

Ainda com relação ao grau de satisfação dos servidores quanto aos cursos do PROCAP, constatou-se que o referido curso consegue proporcionar uma formação profissional que condiz com as obrigações e responsabilidades que são acometidas aos servidores da universidade, pois 59,23\%"dos participantes da pesquisa afirmaram estar satisfeitos com o conteúdo do curso, além disso, 60,52\% deles se consideram satisfeitos quanto a possibilidade de aplicar o conhecimento adquirido durante o curso no seu trabalho diário. Apesar de ser grande o número de participantes que se sentem insatisfeitos com o corpo docente do PROCAP e com recursos utilizados para realização das aulas, como espaço físico, iluminação e equipamentos, a maioria dos entrevistados afirma que estão satisfeitos com o professores e com os recursos oferecidos, sendo o percentual de $53,95 \%$ e de $43,43 \%$, respectivamente. 
Assim sendo, percebe-se que a Universidade de Brasília, por meio do PROCAP, tem conseguido efetivar a sua política de capacitação com sucesso, pois os servidores se demonstram satisfeitos com o curso, a Universidade consegue atender aos públicos interno e externo. 


\section{REFERÊNCIAS}

- ABBAD, G.S.; FREITAS, I. A; PILATI, R. Contexto de trabalho, desempenho competente e necessidades em TD\&E. In: BORGES-ANDRADE, J.E.; ABBAD, G.S.; MOURÃO, L. e colaboradores. Treinamento, desenvolvimento e educação em organizações e trabalho: fundamentos para a gestão de pessoas. Porto Alegre: Artmed, 2006. cap. 12.

- ARROYO, Miguel. Avaliação de Programas de Capacitação de Profissionais para a Educação Rural. In: Capacitação de Profissionais da Educação: perspectivas para avaliação. Belo Horizonte: Ministério da Educação, 1987, cap. I, p. 69.

- BOOG, Gustavo G. Manual de Treinamento e Desenvolvimento: um guia de operações - manual oficial da ABTD. São Paulo: Makron Books, 2001. p. 78.

- BOUDON, Raymond . Os Métodos em Sociologia. São Paulo: Ática, 1989. p. 24.

- CORREIA, Jacinta Castelo Branco. Comunicação e Capacitação. Brasília: lattermund, 1995. p. 15-17.

- FLEURY, Maria Tereza L; OLIVEIRA Jr.; Moacir de Miranda (Org.). Gestão Estratégica do Conhecimento: integrando aprendizagem, conhecimento e competências. São Paulo: Atlas, 2001.

- FERREIRA, Elizabeth de Araújo (Org). Universidade de Brasília. Secretaria de Planejamento. Anuário Estatístico UnB: Brasília, 2004, p. 231.

Planejamento. Anuário Estatístico UnB: Brasília, 2005, p. 243.

(Org). Universidade de Brasília. Secretaria de

- VIEIRA, Eduardo Tadeu; MIZUNO, Roberto (Org). Universidade de Brasília. Secretaria de Planejamento. Anuário Estatístico UnB: 2006, P. 209.

- GARVIN, D. A. Gerenciando a qualidade: a visão estratégica e competitiva. Rio de Janeiro: Qualitymark, 1992.

- PILATI, R. História e importância de TD\&E. In: BORGES-ANDRADE, J.E.; ABBAD, G.S.; MOURÃO, L. e colaboradores. Treinamento, desenvolvimento e educação em organizações e trabalho: fundamentos para a gestão de pessoas. Porto Alegre: Artmed, 2006. cap. 8.

- Plano Anual de Capacitação do Sistema MinC - PAC 2007. Brasília: Ministério da Cultura, 2007. 
- PlANTULLO, V. L. Treinamento e Desenvolvimento de Empresas: Análise de Modelos. Curitiba: Juruá, 2008.

- Resolução do Conselho de Administração № 003/2002. Brasília: Universidade de Brasília.

- TAMAYO, Natasha; ABBD, Gardênia da Silva. "Autoconceito profissional e suporte à Transferência e Impacto do Treinamento no Trabalho.", Revista de Administração Contemporânea - RAC, Rio de Janeiro - RJ, v. 10, n. 3, 2006, p. 9-28.

- VARGAS, M.R.M.; ABBAD, G.S. Bases conceituais em treinamento, desenvolvimento e educação - TD\&E. In: BORGE-ANDRADE, J.E.; ABBAD, GS.; MOURÃO, L. e colaboradores. Treinamento, desenvolvimento e educação em organizações e trabalho: fundamentos para a gestão de pessoas. Porto Alegre: Artmed, 2006. cap. 7. 
ANEXOS

- Questionários. 


\section{ANEXO \\ QUESTIONÁRIOS}

Visão dos servidores da Universidade de Brasília sobre os cursos do PROCAP.

1) Perfil do Servidor

1) Faixa Etária:

- 18 a 29 anos ( )

- 30 a 39 anos ( )

- 40 a 49 anos ( )

- 50 a 60 anos

- Acima de 60 anos ( )

2) Sexo:

- Masculino ( )

- Feminino ( )

3) Escolaridade:

- Ensino fundamental

- Ensino Médio

- Curso Superior

- Pós-Graduação

4) Situação funcional:

- Técnico do Quadro

- Terceirizado

- Outro

2) Questionário específico ao PROCAP

1. Quantas vezes realizou curso do PROCAP? (marque com "X”)

De uma a três vezes 
De quatro a seis vezes ( )

De sete a dez vezes

2. Você teve problema de liberação do seu expediente de trabalho para realização do curso?

$\operatorname{Sim}()$

Não ( )

\section{3) Questionário de grau de satisfação}

As questões a seguir deverão ser respondidas de acordo com seu grau de satisfação. Para isso basta marcar com um " $X$ " na coluna relativa ao grau de satisfação conforme a tabela a seguir.

\begin{tabular}{|l|l|l|l|}
\hline 1- muito satisfeito & 2 - satisfeito & 3 - insatisfeito & 4 - muito insatisfeito \\
\hline
\end{tabular}

\begin{tabular}{|c|c|c|c|c|c|}
\hline \multirow[t]{2}{*}{$\mathrm{N}$} & \multirow[t]{2}{*}{ Questões } & \multicolumn{4}{|c|}{$\begin{array}{l}\text { Graus de } \\
\text { Satisfação }\end{array}$} \\
\hline & & 1 & 2 & 3 & 4 \\
\hline 1 & $\begin{array}{l}\text { O curso do PROCAP proporcionou uma melhora substancial na } \\
\text { sua cultura geral? }\end{array}$ & & & & \\
\hline 2 & $\begin{array}{l}\text { Proporcionou melhora significativa das principais abordagens do } \\
\text { mundo do trabalho (relação interpessoal, clareza nas decisões, } \\
\text { uso de novas tecnologias)? }\end{array}$ & & & & \\
\hline 3 & $\begin{array}{l}\text { Houve interação entre o conteúdo oferecido pelo curso e o } \\
\text { desenvolvimento das atividades exercidas na Universidade de } \\
\text { Brasília? }\end{array}$ & & & & \\
\hline 4 & $\begin{array}{l}\text { É possível aplicar o conhecimento adquirido durante o Curso no } \\
\text { seu trabalho diário? }\end{array}$ & & & & \\
\hline 5 & O corpo docente do PROCAP demonstra qualificação adequada? & & & & \\
\hline 6 & $\begin{array}{l}\text { Os recursos matérias/financeiros na Universidade são adequados } \\
\text { (sala de aula, equipamento, luminosidade, sanitário, bebedouro, } \\
\text { cantina)? }\end{array}$ & & & & \\
\hline
\end{tabular}


